\title{
Surgeons, surgeries, and operating rooms in television medical series
}

The longest-running American prime-time television medical series, Grey's Anatomy represents a society in which gender is not a potential career barrier in surgery. Focusing on an iconic scene of the series, this article brings media studies together with the history- and philosophy of surgery to provide a qualitative analysis of this portrayal on three levels: surgical procedure, protagonist, and place. Following previous studies on medical drama series, the theoretical framework of the article is cultivation theory. Some elements of the genre - like the realistic hospital setting and the authentic usage of medical jargon - might strengthen the likelihood of content cultivation. Finally, I discuss the potential positive and negative effects of the way how this popular series depict female surgical careers.

Keywords: television, medical drama series, popular culture, medicine, cultivation theory

\section{Author Information}

Eszter Nádasi, Budapest University of Technology and Economics https://szoc.bme.hu/hu/home-hu-hu/munkat\%C3\%A1rsak/21-n\%C3\%A1dasi-eszter.html

How to cite this article:

Nádasi Eszter. "Surgeons, surgeries, and operating rooms in television medical series." Információs Társadalom XX, no. 2 (2020): 33-54.

$=\quad$ https://dx.doi.org/10.22503/inftars.XX.2020.2.3 $\rightleftharpoons$

All materials

published in this journal are licenced

as CC-by-nc-nd 4.0 


\section{Introduction}

Successfully finishing a life-saving abdominal surgery, Meredith Grey (Ellen Pompeo), attending general surgeon, stands in the operating room and watches the broadcast of the Harper Avery Award Gala. As one of the candidates for this distinguished surgical prize, Grey should be at the ceremony; however, she decided to operate instead. She is a nominee because of the game-changing abdominal wall transplantation technique she developed. Grey wins, which means her innovation is the most remarkable surgical achievement of the year. Her colleagues celebrate Grey in the OR, and its gallery: in the crowd, there are outstanding female surgeons from different racial backgrounds. The representative of the prestigious Harper Avery Foundation is a black female surgeon. Surgery is an open field for talented, hardworking people, regardless of their gender and race. At least, this is what the long-running, award-winning television medical drama series, Grey's Anatomy, represents about surgical careers.

Television medical drama series are "pre-scripted, fictional entertainment television shows in which the main events occur in hospitals and the main topics are the diagnosis and treatment of disease or injury" (Lee and Taylor 2014, 14). The first medical drama premiered in 1952 (City Hospital), and despite some downturns, the genre is still popular. Surgeons are core characters of the genre from its early days: the two highly successful medical series of the ,60s ( $D r$. Kildare and Ben Casey) both had surgeon protagonists (Turow 2010).

Academic receptions of medical drama series highlighted that these productions serve as an information source for the audience (Murphy et al.2008; Rideout et al. 2008; Jan and Slater 2013; Lee and Taylor 2014; Jessica Bodoh-Creed 2017). Previous empirical studies and content analyses investigated how medical drama series affect the knowledge, attitude, and behavior of the audience towards specific themes that appeared in these productions. By applying a survey method, Brian L. Quick (2009) examined the cultivation effects of Grey's Anatomy's doctor representation - the concept of cultivation theory will be explained later in this chapter. According to the results, the more someone watches this show, the more someone tends to believe that the content is credible and accurate. Those who believe in the show's accuracy tends to think that real-world doctors are brave, just as the characters of the show. Doctors representation and the role of medical dramas in shaping the viewers' predisposition of doctors were examined by other researchers (Pfau et al. 1995; Chory-Assad and Tamborini 2001; Chory-Assad and Tamborini 2003; Jain and Slater 2013; Mickel, McGuire and Gross-Gray 2013; Pokhrel and Lok 2015). Cultivation effects of the genre were discussed regarding transplantation (Harbaugh et al. 2011; Kupi 2011; Kahil et al. 2014; Quick et al. 2013), bioethics (Czarny et al. 2010), death (Houben et al. 2016; Freytag and Ramasubramanian 2018), and medical malpractice (Foss 2011). Another group of studies examined whether medical drama series can be used as entertainment education source for the lay audience (Cooper, Roter and Langlieb 2000, Brodie et al. 2001; Valente et al. 2007; Hether et al. 2015; Kato et al. 2017). Many studies 
focus on learning CPR from the screen (Diem et al. 1996; Gordon et al. 1998; Van den Bulck 2002; Eisenman and Stolero 2005; Bridley 2009; Harris and Willoughby 2009; Hinkelbein et al. 2014; Portanova et al. 2015). Others examine how products of this genre provide role models for future healthcare professionals and investigate whether medical series can be elements of their bioethics and communication curriculum or not (Czarny et al. 2008; Spike 2008; White 2008; Wicclair 2008; Arawi 2010; Weaver and Wilson 2011; Hirt et al. 2013; Weaver et al. 2014; Hoffman et al. 2017; Kendal and Diug 2017).

Created by Shonda Rhimes, Grey's Anatomy premiered in 2005, and currently, it has 16 complete seasons, 356 episodes - this is the longest-running American prime-time medical drama series in the history of television. Progress of medicine is a core plot element in this popular series; most of the surgeon characters are innovating their field of work. The series represents innovations in a technological and a social sense as well. As Linsay M. Cramer writes, creators of the series "rhetorically construct a narrative of progress - medical, technological, and social, and therefore, racial. The merge between two of the show's major focal points, medical advancements (and thus medical technologies) and interracial relationships, functions to situate the show as an authority on >>social progress<<" (Cramer 2016, 476). The center of the show, the Grey-Sloan Memorial Hospital as a metropolitan research hospital, signifies the show as a future-oriented and progressive one. Cramer critically analyses the postracial society depicted in the series in which race creates no professional or personal boundaries for the non-white characters.

This article uses the approach of Cramer and extends it to gender because Grey's Anatomy represents a society in which gender is not a potential career barrier anymore in the field of surgery. Is it an authentic representation of the domain? What are the possible effects of this representation? These questions are relevant because, since its beginnings, Grey's Anatomy gives inspiration ${ }^{1}$ and courage for females from all over the world to build a career in medicine, even in surgery.

By using the above-described scene as a starting point, this study explores how Grey's Anatomy represents the role of surgery, surgeons, and surgical units; furthermore, it discusses the messages and social importance of these representations. Following previous studies on medical drama series, cultivation theory as a theoretical framework is applied. As Morgan and Shanahan $(2010,337)$ write, „cultivation analysis investigates television's contribution to viewers' conceptions of social reality” Furthermore, „a meta-analysis of over two decades of cultivation research showed that television viewing makes a small but consistent contribution to viewers' beliefs and perspectives" (Morgan and Shanahan 2010, 340). The con-

1 Grey's Anatomy' star Ellen Pompeo reacts to the women she inspired to pursue medical careers: https://abcnews.go.com/Entertainment/greys-anatomy-star-ellen-pompeo-reacts-women-inspired/story?id=51035189 (03rd June, 2020) 
cept of cultivation was developed by George Gerbner in the 1960s: today, it is one of the three most cited theories of mass communication research published in prestigious scholarly journals from 1956 to 2000. Despite the changing media environment, cultivation is still popular: beyond the analysis of the overall television content, scholars also examine the cultivation effects of certain genres or even single programs (Morgan and Shanahan 2010). As Hawkins and Pingree reported, „cultivation effect is genre specific and concluded that the formulas and conventions unique to different TV genres are responsible for cultivating subtly different views of the world" (Grabe and Drew 2007,151). Following this trend, this article focuses on Grey's Anatomy, but discussing those elements of the medical drama genre that have an impact on the reception of this production. As Grabe and Drew states, perceived realism of content influences the cultivation process. For this, they bring the example of crime dramas: a high level of perceived realism leads to a higher fear of crime. I argue that some aspects of the medical drama genre - like the hospital setting and the usage of medical jargon - affects the audience's perception of realism, thus strengthen the likelihood of cultivation.

This article brings media studies together with the history and philosophy of surgery to provide an elaborate analysis of the selected scene. The investigation of the series' content builds on qualitative research methods, narrative-, and character analysis. The analysis of the selected scene has three main segments procedure, protagonist, and place. All segments have two levels: reality and representation. The procedure part starts with a historical contextualization of abdominal wall transplantation and its cultural meanings; then, it explores the positioning and ethical considerations of the procedure as it is represented in the series. By focusing on the show's protagonist, the second segment describes the status of American female surgeons in the past and present, and the evolution of the character type in the American medical drama series. Finally, operating rooms are the locations where technical and social innovations come into existence according to the series. Thus, the last part regards the place by interpreting the core principles of the real operating room setting and the way how these locations are represented in the medical series. The discussion section examines the potential cultivation effects of Grey's Anatomy surgeon representation by highlighting the benefits and harms. Finally, the article provides an overview of other medical dramas that might reinforce and contradict the message of the analyzed series.

\section{Procedure: abdominal wall transplantation}

\subsection{Reality}

This part of the study examines the surgical field in which Meredith Grey gain great successes and contextualize her award-winner procedure. 
As the study of Sally Frampton (2018) clarifies, abdominal operations have a significant role in the history of surgery. Before the 19. century surgical procedures tend to focus on the surface of the body; diseases of inner organs were treated with non-invasive medical approaches. The abdomen used to be regarded as a mysterious and dangerous area, and it was opened only in exceptional cases, for instance, in the case of Cesarean sections and life-threatening traumatic injuries. However, by the end of the century, after the introduction of antiseptic practices, abdominal surgery started a rapid development, and organs of the abdomen become the primary scope of operations. Based on a reductionist approach, surgeons aimed to localize the reparable areas of the human body and used different manual techniques and equipment to fix these. In the beginning, most of the abdominal surgical procedures were applied to female reproductive organs. Ovariectomy, for instance, became a common intervention that was practiced for medical and psychological reasons, for example, to treat hysteria. According to the Victorian viewpoints, females are defenseless; thus, they need to be rescued by the paternalist male doctors. The digestive system also provided challenges for the surgeons, as this area of the human body was regarded as the core of ill-health, and this concept reinforced the developing surgical field that provided treatments for more and more conditions. For the beginning of the 20th century, surgeons consolidated their elite position in the medical society; they were respected by professionals and laypeople as well.

However, by the middle of the century, surgery became an umbrella term that covered respectable surgical sub-fields, and the original field of abdominal surgery got the name "general surgery" (Kernahan 2018). It was a stable and stagnated area, other surgical fields, just as the cardiothoracic specialization provided more innovative procedures. In the, 80 -as, minimally invasive, laparoscopic surgical procedures were invented and became successful nearly instantly. Despite this, invasive, exploratory abdominal surgeries still have an essential role, for instance, in traumatology and transplantation.

According to Sibylle Obrecht (2018), experimentations with transplantation have already existed in the 19. century when surgeons tried to prove their place in the prestigious medical society. Early trials tend to focus on the functional reparation of organs; thus, the surgeons did not necessarily exchange the anatomically identical body parts, or they did not implant the new organs to their anatomical place in the body. With these approaches, they gained short term successes, because of the lack of knowledge on immune reactions. The two world wars slowed down the development of transplantation since the surgeons were busy with the treatment of wounds. After the ,40s, the differences of the donor-recipient body became a field of theoretical interest, and clinical trials became more widespread again in parallel with the scientific explosion of the period. For the ,60s, transplantation was an established surgical area and symbols of modern surgery. The practice of transplantation points out how medicine is capable of destabilizing and rewrite societal and 
cultural values such as the demarcation lines between the living and dead bodies or between the self and others. Transplantation entails a series of biological, legal, and ethical questions. It transmits a view according to which the elements of the living body can be replaced that is a mechanical and reductionist understanding of human existence.

Abdominal wall transplantation is an existing, challenging, and not yet a routine procedure. There are patients whose condition cannot be solved with the traditional reconstructive surgical techniques, and for them, complex abdominal wall transplantation is a potential solution (Light et al. 2017). An indication behind the procedure is the common complication of intestinal organ transplantation and the difficulty of surgical wound closure (Quigley et al. 2013). According to a review article, „several centers have already proved the technical and immunologic feasibility of partial or full-thickness abdominal wall transplantation" (Giele et al. 2016). In the examined cases, the researchers identified different surgical techniques for abdominal wall transplantation - Grey's Anatomy reflects on this variety.

\subsection{Representation}

As Obrecht (2018) states, the exchange of body parts and organs between different people is a popular topic among writers and journalists from the beginning of the 20th century. The arts, the entertainment industry, and the media displayed the development of transplantation and its ethical dilemmas. Transplantation in a recurring plot element of medical drama series; however, these productions are often criticized because of the way how the organ donation system, organ harvesting, and transplantation surgeries represented.

The portrayal of these processes is a sensitive issue in America: there is a growing need for donor organs, but the number of donors does not grow. The transplantation system builds on voluntary registration: those who wish to be organ donors need to make a direct confess in their life. After death, if someone made no confess, the adherents make the decision. Negative transplantation representation is capable of compromising viewers' beliefs, attitudes, and actions towards the procedure. As Harbaugh et al. (2011) and Quick (2014) state, the lay audience tends to regard the media as an information source, especially in those topics that are not familiar for them: limited or no personal experience with transplantation makes them relay on the media and the entertainment industry. Prime-time infotainment programs and medical series usually have emotionally engaging storylines that eventuate a more significant potential effect on the audience.

Harbaugh et al. content analyzed nine medical series (235 episodes in sum) and identified five potentially harmful representation pattern: 
1. doctors, led by their interest, play the transplantation system

2. surgeons wait like „vultures” to harvest organs

3. in some cases, doctors let the donors die, or even murder them

4. doctors do not see the human being in the donor

5. the healthcare system is a part of the black market for organs.

Kupi's (2010) narrative analysis focuses on the first five seasons of Grey's Anatomy (102 episodes), and she identified seven harmful narratives. Some of these are similar to Harbaugh's findings: the transplantation system is corrupt; the recipient is more important than the donor - thus, doctors do not do everything for the donor. Furthermore, donors get no empathy or mercy; doctors control the life or death of brain death patients by the usage of technology in an anti-humanistic manner. Additionally, through transplantation, the integrity of the body is harmed, personal characteristics of the donor can be transferred with the organs. Medical series tend to represent the waiting list as a death list, and donor organs are sometimes wasted. The more positive narratives celebrated the advancements of transplantation. Kupi differentiates the visually naturalistic representation of organ harvesting and the elated scenes of implantation. According to her, in many cases, it seems that the surgeon does not treat humans; instead, they operate on bodies that built up from mechanical components.

On the contrary, medical series Three Rivers provide a more positive representation: as Khalil et al. (2014) concluded, the series contradicted four harmful myths about transplantation. In this series, doctors do not make decisions about organ distribution, and they do everything for registered donors. The series reinforces that famous people do not have advantages in the system, and family members do not need to pay for the organs. The researchers made a content analysis first and then a survey (1325 respondents): according to the results of the empirical research, the positive representation had a positive effect on the audience.

\subsection{Plot analysis: procedure}

Following the conceptualization above, this section analyses the depiction of the abdominal wall transplantation in Grey's Anatomy.

After ten years of captivity in Iraq, an American female soldier is rescued. Megan Hunt served as a traumatologist in the army when the enemy kidnapped her and took advantage of her knowledge. She got a massive, threatening abdominal wound in a bombing. Her doctor Meredith Grey applies an established, reparation based surgical procedure, but it is not working. Grey tries to come up with a solution at her home, where she realizes that her wallpaper ruined again. She states that it must be replaced not fixed - and at this 
point, she finds an analogy between the case of the abdomen and the wallpaper. From this sudden discovery, Grey develops an abdominal wall-transplantation method, which is an improvement of an already existing procedure. The difference is that Grey does not do organ transplantation as a part of the process, just closes the wounded abdominal wall. Hunt trusts in the new procedure an encourages the surgeon to do it. The residents compete to find a suitable donor, and the hospital provides financial funding for the operation. The surgery has an excellent outcome: it saves Hunt, and the procedure will help many people in the future; furthermore, Grey gets a prestigious award for it.

This storyline points to some aspects of the history of surgery. War injuries are traditionally seen as starting points for surgical developments (Bergen 2018). Surgeons tend to engage in trials not only to establish brand new procedures but to develop and alter the already existing ones. Surgical trials are different than pharmaceutical ones since the randomized, double-blind method is not always applicable in surgery. Furthermore, the amount of theoretical research and laboratory work is smaller than in other fields of medicine and, more broadly, science (Jones 2018). The storyline reinforces the social acceptance of transplantation as a healing procedure - it mirrors the hopes and optimism towards it (Obrecht 2018). There are cases in the history of surgery when the patients' support, encouragement, and bravery were needed for the trials of new procedures (Snow 2018). Moreover, this storyline displays the traditional ideal of a surgeon who is capable of dividing their emotions from the profession: Grey and Hunt have the same love interest, but despite this, Grey saves her competitor (Brown 2018).

In summary, the protagonist succeeds in a historically significant field of surgery, which unique prestige started to be shadowed by for instance operations on the brain and the cardiothoracic area. However, abdominal surgery and general surgeons played a vital role in the history of medicine, and this storyline reconfirms this heritage and suggests that there is still a considerable innovative potential is this surgical field. At the age of minimally invasive surgeries, Grey treated a traumatic injury and succeeded with an invasive procedure that creates a big wound in the body that is sensitive to infections. However, she practiced one of the most prestigious, complicated, and risky procedures of modern surgery: transplantation. Abdominal wall transplantation is an existing but challenging procedure, and Grey's Anatomy provides an ethically problematic representation of it. The competition of the residents to find a donor is a negative representation of transplantation since it reinforces the fear that donors are not valuable for surgeons; they are new body parts, sources of replacement for the indeed significant recipient. Also, the hospital provides money for the surgery, supposedly because Megan Hunt is herself a surgeon, and her brother works at the Grey-Sloan Memorial as a traumatologist - the latter suggests that relatives of the doctors get advantages in the transplantation system. Despite these plot elements, the general framing of the procedure is quite techno-optimist. 


\section{Protagonist: female surgeon}

After a historical overview, this section discusses the contemporary situation of female surgeons first; then, it examines the evolution of the female surgeon character type in television medical dramas.

\subsection{Reality}

In America, the participation of women in medical education was prohibited until the middle of the 19th century. Even later, they were held back from the surgical specialty since surgery was traditionally seen as a masculine field of medicine. As Wirtzfeld (2009) writes, Elizabeth Blackwell (1821-1910) was the first American female doctor. Her friend died in cancer that motivated Blackwell to become a doctor and focus on the female reproductive system and to provide a "gentler hand" for female patients. She graduated in 1849 in the Geneva Medical College, but she could not start her surgical residency in the USA. She worked as a midwife in France, and because of an infection, she lost her left eyesight; thus, she had to give up her surgical ambitions. In 1862 she opened the Women's Medical College in New York, but she argued for integrated medical education. Graduated in 1855 at the Syracuse Medical College in NY, Mary Edwards Walker (1832-1919) became the first American female surgeon. For a couple of years, she worked with her surgeon husband, but her practice failed. She became the first female surgeon of the army; however, she served there as a nurse for years (Wirtzfeld, 2009). In 1941 the first Black woman got her medical degree: Dorothy Lavinia Brown (1919-2004), and she became the first Black woman who became a member of the American College of Surgeons (McLemone et al. 2012).

What is the reason behind this gender-related discrimination among doctors? As Brock states, the potential entrance of women to surgery was criticized, it was often called unimaginable, unacceptable, and undesirable (Brock 2013). However, female surgeons practiced in Europe even before they could legally enter the specialty: from the Victorian era, they served as a pro-argument for female surgeons. Another significant argument was that female patients might be more comfortable with women doctors. At the same time, before the age of anesthesia, operations required physical and mental strength, and women were not associated with either. Thus, even the male supporters of female participation in medicine tried to hold back women from this specialty. But with the technological advances, surgery, and the ideal of the surgeon had changed. World War I. also brought change: male surgeons served on the fields; females replaced them in civil hospitals (Brock 2018). Interestingly, Elizabeth Blackwell criticized female surgeons because they behaved like their male colleagues - as a reason for this, she named the education system in which women learn from men and the atmosphere in the surgical department created by men (Brock 2013). 


\subsubsection{Contemporary status of female surgeons in the US}

Nowadays, direct discrimination of female surgeons is prohibited; however, they still need to face several challenges. In 2018 Brock stated that the amount of female surgeons is lower in surgery than generally in medicine - this is the case in the United States, Australia, New-Zealand, Great-Britain, and the Scandinavian countries (Brock 2018). According to the statistics of Wirtzfeld: until the ,70s, the amount of female medical students in America and Canada was $6 \%$ maximum.

- In 1970 only $5 \%$ of doctors were female in the USA; for 2001, this rate was $24 \%$, and in 2009 the gender division of medical school applicants was nearly balanced (47,3\% female applicants).

- In 1913 the American College of Surgeons accepted the first female member, Florance Duckering, and until 1975 the number of female members was 0-5 annually; in surgical specialties, their rate was under $2 \%$. In 1980 the amount of female surgical residents was 2\% (but this number includes gynecologists and obstetricians); for 2001, this rate was $14 \%$ (Wirtzfeld 2009).

McLemore et al. published similar numbers; according to them, a considerable number of female surgeons appeared in the late ,80s and ,90s. In 2010, $35 \%$ of the applicants for general surgery resident programs were female. But the number of women is under $15 \%$ in cardiothoracic-, neuro-, orthopedicand urologic surgery. McLemore et al. also highlight the problem of the glass ceiling effect in case of academic positions: $41 \%$ of assistant professors are female, this number is $29 \%$ among associate professors, $17 \%$ professors, $19 \%$ tenured professor. The rate of female heads of departments is only $12 \%$ (McLemore et al. 2012).

A new study of Pories et al. reinforces that the number of female leaders in medicine has remained low until recently. But nowadays, „more women are now rising to leadership positions in surgery, both in academics and within surgical organizations (...). However, increasing the number of underrepresented minority women in leadership positions remains an opportunity for improvement." On its website, the Association of Women Surgeons (AWS) lists the female chairs in surgery. This group supports female surgeons at various career stages. Currently, the American Surgical Association (ASA) has a female committee president, Robin S. McLeod. Among the ASA Foundation - Fellowship Recipients, there are females.

Wirtzfeld et al. summarize qualitative research on female surgeons. There are several reasons why women select surgical specialty: inspiring female and male role-models; the intellectual and technical challenge; they believe that their personality fits the specialty. Some factors hold back women from surgery, for example, the lack of encouragement, the perception of the specialty of a challenging, time consuming, not family-friendly one that provides a 
non-controllable lifestyle. Brock (2018) also stated that there are still boundaries between women and surgery, like the work-life balance, the professional network in the workplace, and the lack of suitable role models.

Furthermore, female surgeons face other challenges. According to a survey study, 58\% of their American female surgeon respondents experienced sexual harassment within 12 months (Nayyar et al. 2019). As another report shows, $31,9 \%$ general surgeon residents experienced gender-based discrimination; $16,6 \%$ racial discrimination; 30,3\% was a victim of verbal or physical abuse or both; and 10,3\% has sexual harassment in their workplace. Women experienced more mistreatment than men: $65,1 \%$ of female respondents reported gender discrimination - a frequent source of it is the patient or their family, just as in the case of race-based discrimination (Yue-Yung Hu et al. 2019). In conclusion, it is not impossible to succeed as a female surgeon today, but there are still gender-related career barriers on the way.

\subsection{Representation}

Representation of female scientists in the popular culture already has academic reception (Flicker 2003; Haynes 2017). Fictional images of science in books, films, and series tended to build on male characters. Similarly, medical dramas used to depict medicine as a masculine field; early productions had only male protagonists. In medical series, female doctor characters have come a long way to the TV screens. Building on Joseph Turow's monograph, this section overviews the evolution of the character type from the ,50s until the premiere of Grey's Anatomy. From 2005, I apply the findings of my Ph.D. research.

Female doctors and surgeons appeared much sooner in hospitals and operating rooms than on the television screen. Before the ,70, television medical series did not include female doctor characters; it was the period of the white medical kings. The first trials with the new character type were unsuccessful - as show creators stated that the genre mainly has a female audience and the wish to watch handsome male protagonists. The first medical series with a female protagonist was the Having Babies (ABC, 1978), in which Susan Sullivan played the gynecologist-obstetrician Julie Farr. For the failure, the lousy script was also blamed. Dr. Quinn, Medicine Woman is not a typical medical drama, instead a medically themed period drama that had more significant success in the early ,90s: the representation of the 19th-century wild-west is one potential component of its success. At the time of scientific progress, the protagonist faces the discrimination and prejudices of the era: she cannot attend a regular medical university, so she graduates in a female college. Her father was a metropolitan doctor, he took the risk to work with his daughter, but after his death, the woman was not accepted by the patients anymore. She moves to Colorado Springs, but in rural America, she gets no respect and has no medical authority at the beginning. 
In $1994 E R$ started to promote a more inclusive picture of doctors. The series had 15 seasons, and it has nine female protagonists, including emergency specialists and surgeons at various career stages (medical trainee, resident, chief resident, attending, department head). Female protagonist had a different racial and ethnic background, their sexual orientation was also diverse. However, Chicago Hope premiered in the same year with no female doctor characters. New characters appeared from the second season, including female cardio- and neurosurgeons, but the rate of male and female doctors remained unbalanced. A successful medical series of the 2000s, House $M D$, presented a female endocrinologist as a hospital director; and the show had a female emergency specialist, immunologist, an internalist, and a prison doctor female character. In 2005 Grey's Anatomy debuted with a female protagonist, Meredith Grey, whose name appears in the title of the production. However, the male protagonist, Derek Shepherd (Patrick Dempsey) was her strong competitor until Dempsey left the series in 2015. The series was a great success from its beginning; thus, in 2007, the first spin-off, Private Practice came to the screen with also a female protagonist, gynecologist-obstetrician Addison Montgomery (Kate Walsh).

Despite these positive tendencies, not every medical drama series succeeded with a female protagonist: Emily Owens M.D. and Heartbeat had only one season. New medical dramas of 2010 (Chicago Med, Code Black, New Amsterdam, Night Shift, The Good Doctor, The Resident) had no solo female protagonist, but these productions regularly displayed competent women doctors. The Knick as a historical medical drama reflected on the gender-based discrimination in medical education that was a characteristic of the early 20th America.

\subsection{Plot analysis: Protagonist}

This part analyzes the character development of Meredith Grey by focusing on the professional parts and among these the research and innovation related storylines. The way how Grey's Anatomy presents the situation of female surgeons is also discussed.

In season 1, Grey started her residency program, and by the time she wins the Harper Avery, she is the head of the general surgery department. In the early seasons, she planned to select the prestigious and competitive neurosurgery specialization, but after misconduct, she got a prohibition. Thus, she decided to orient on general surgery - as described above, this specialty is the most traditional field of surgery. However, operating on the abdomen is not as prestigious today as it was in the early period of modern medicine (Norredam and Album 2007).

Regarding surgical innovation, Grey had to wait for the success: before the abdominal wall transplantation, two of her formal trials had failed. As a talented resident, she served as a research assistant in an Alzheimer's trial, and she violated the methods of the standardized, double-blinded clinical trial to help a patient she knew for a long time (Season 7). Later, at the beginning of 
her career in general surgery, she aimed to 3D-print a liver graft, and for this, she did systematic laboratory trials and surgeries on test animals. While being stuck with the project, Cristina Yang (Sandra Oh), a cardiothoracic surgeon, got the printer to create a heart conduit to help a patient. According to Yang, Grey professionally withheld by her kids.

Interestingly, Yang was nominated for the Harper Avery Award, but she never won it. The story of the 3D printer implies that instant life-saving is a priority comparing to a long-term research project, the authority of cardiothoracic surgeons, and the drawback of mothers among surgeons (Season 10). Later seasons of the series represent a more empowering image of female surgeons in which the family is not such a direct barrier for women. According to the rhetoric, every woman can succeed in surgery: talent and hardworking attitude are the only factors that matter. Grey's female colleagues perform in highly prestigious fields of surgery like cardio- or neurosurgery, and in specialties that required physical strength in the past just as traumatology and orthopedic surgery. Among them, there are heads of departments and chief residents. In the world of Grey's Anatomy, specialties with a high number of female professionals do not lose their prestige as being „pink-collar” fields contrary to reality (Norredam and Album 2007).

The series represents discrimination and glass ceiling as the history of medicine. It happens by the introduction of Ellis Grey's career: the award-winning surgeon is the protagonist's mother who had to fight for being accepted as a surgical resident. Similarly, sexual harassment positioned as harm experienced by the generation of elder Grey.

Among the characters, there are indeed competent male surgeons, so the empowering female representation does not build on the absence of a male doctor or the diminishment of male surgeons' competency and achievements in the surgical field. Some of the male characters embody the traditional white, masculine surgeon ideal; others have a diverse racial background. Female surgeons are equally competent, confident, and powerful as their male colleagues, they have the same amount of authority, and these tendencies represented as natural in the present time of the series.

\section{Place}

\subsection{Reality}

As historian Thomas Schlicht (2007) writes, power and authority of surgeons come partly from their work environment. The space of the OR provides permission for the invasive procedures that would be unacceptable outside this space without proper medical indication. Operating theaters are distinctive hospital areas; however, even from the period of modern surgery, these plac- 
es went through significant changes. In her architectural study, Annamarie Adams (2018) differentiate three periods: the age of Victorian amphitheaters, surgical suites, and operating rooms.

Like colosseums and opera houses, Victorian amphitheaters are monumental buildings that allow many people to witness the operations. It has minimal contact with the patient wards; in cases, it is placed at the edge of the hospital, or even in a separate building. Amphitheaters usually have a cloakroom, lobby, and restroom for the audience. Its entrance is visible from the street, and windows are big enough to let sunlight ${ }^{2}$ in. The operating table fixes the patient in the middle of the space where the surgeon takes a central position, other doctors, medical students, family members of the patient, and those who are interested in operations take their seats around them. The surgeon performed as an actor to provide verbal interpretation for the audience. There was no boundary between the operating area and the viewers; before the 1880s, surgeons had no scrubs for the operation - it was the period before the establishment of antiseptic and aseptic surgery. For the beginning of the 20th century, sterilization areas and restrooms for operated patients appeared, smaller amphitheaters became widespread, but hospitals started to have more than one amphitheater. In this period, parallel operations began with the exclusion of the audience.

Then the operating area moved to the inner space of the hospital, usually upstairs. The new surgical suits were smaller and less spectacular than the amphitheaters; from the outside, these were like other hospital areas. Influenced by the avant-garde, some suits had an extraordinary architectural arrangement, identical to domes or eggs. Galleries with plastic or glass became universal, to host the professional audience - sound systems and binoculars helped them to witness the operation. The big surgical lecture as a teaching method became outdated; the new trend was to let smaller groups of students to the suits and let them watch the operation closely.

Operating rooms are private spaces, invisible from the outside, isolated, not available for those who are not authorized. Hospitals started to have multiple, identical, artificially lighted, and ventilated ORs with common preparation areas. This work hyper-sterile environment is not affected by any influence from outside; the surgeon has complete control - the OR is like a bubble inside the hospital.

\subsection{Representation}

Medical series are professional dramas in which „the plot, the characters (...) are defined by and dependent on a specialized professional environment' (Laudisio 2018). As the location is a central plot element, this genre depicts realistic hospi-

2 Later artificial lighting provided more control to the surgeons, they became less dependent on the daypart and the weather. 
tal settings from its early years (Turow, 2010). Medical dramas tend to enhance the feeling of reality and accuracy; for this, show creators mix facts with fiction. State of the art medicine appears in an imaginary healthcare system where the financial sources are unlimited, or real-life technological advancements come into existence because of fictional romantic storylines. Symbols of the medical profession (stethoscope, white coat) appear on the screen together with the visual displays of medical specialties (scrubs on surgeons, plastic cover on emergency doctors) and naturalistic depictions of injuries, disease, and their treatment. The fictitious doctors use proper medical jargon, they refer to prestigious real hospitals, and the usage of titles demonstrates the professional hierarchy of the healthcare system. Locational realism means that fictional hospitals look real with their furniture, equipment, spatial arrangement, and colors. As my previous studies on medical series (Nádasi 2016, 2017) argues, these productions provide insight into those places of hospitals that are familiar for laypeople (corridors, patient rooms) and to the hidden spaces (OR, laboratory, sterilizing areas). The feeling of familiarity makes the representation of hidden spaces more convincing.

Despite these shared characteristics, the atmosphere of hospitals in medical series is quite different. Historical medical dramas tend to represent the Victorian amphitheaters - for this, Adams brings the example of The Knick: the OR of the fictional Knickerbocker Hospital modeled after the OR of the real New York-Presbyterian Hospital. In many cases, the scenery presents a nightmare hospital, and this is in parallel with the intention of its director, Steven Soderberg, who did not intend ${ }^{3}$ to raise nostalgia towards the past of surgery; instead, he highlighted the brutality of early 20th century hospitals and operating rooms especially. $E R$ depicted a crowded, metropolitan, public teaching hospital in the 90 s and early 2000: the moderately run-down emergency department and operating rooms displayed in an old building with darkish artificial lighting. It is an ordinary hospital: nothing is too outdated or progressive, the financial limitations of the institution are visible in the setting. Contrary, Grey's Anatomy sets in an ultra-modern but cozy-looking hospital; the lighting is mainly artificial but warmer; the Grey-Sloan Memorial Hospital has big windows and spectacled corridors between different parts of the building. It is indeed a wealthy-looking dream hospital in which the modern environment suggests modern treatment methods (Adams 2018).

\subsection{Plot analysis: place}

The professional center of the Grey-Sloan Memorial Hospital is the surgical department, more precisely, the OR where surgical innovation comes into

3 Steven Soderbergh: ,I wanted The Knick to feel aggressive'. https://www.telegraph.co.uk/ culture/tvandradio/11135879/Steven-Soderbergh-I-wanted-The-Knick-to-feel-aggressive.html (16th August, 2020). 
existence. The sterile and non-sterile area of the operating room is precisely divided. In the selected scene, the surgical team in scrubs and surgical hats just finished a life-saving surgery; they already removed their rubber gloves, masks, and plastic glasses. The operating table is empty and clean. The seconder location of the scene is a gala hall in Boston, where the Harper Avery Foundation hosts a black-tie event in honor of those surgeons who were nominated for the award. Instead of being there, Grey stands where she saves lives daily: in the OR of the Grey-Sloan Memorial Hospital, Seattle. The two mentors of Grey, Richard Webber, and Miranda Bailey, stand behind her during the announcement. At the gallery, her colleagues and family members celebrate her in their scrubs, white coats, and elegant dresses. They are great surgeons, but now they cannot come close to the award- winner in a physical sense. Grey imagines how her mother would be standing in the crowd (the woman who was also a general surgeon died years before). Ellis Grey is in front of her daughter, not behind her, and it also has a symbolic meaning: she was a role model but a strong opponent as well since she criticized her daughter for being ordinary regularly.

Regarding the analyzed storyline, reconstruction has a threefold understanding-first, the new abdominal wall of the patient that needs to be changed. Second, the room of Meredith Grey served as an inspiration for the surgery through the simple fact that it needs new wallpaper. Third, the hospital. Before Hunt's arrival, there was an explosion in the building; thus, some areas are under reconstruction. The bombing in which Hunt got the surgery and the explosion are parallel storylines; there is a direct analogy between the rebuilding of the body and the location. The Chief of Surgery, Miranda Bailey, makes a direct connection between the work of surgeons and the reconstruction workers.

This storyline suggests that the OR is the primary space of surgeons. For Grey, work is more important than her representative role and the celebration of her success. She lives her success in the OR, not in a gala hall. It is a rather committed representation if not workaholic - however, Grey's Anatomy tries to represent surgeons who manage to keep the work-life balance.

\section{Conclusions}

This part discusses the overall importance of television representations by giving a theoretical explanation, an analysis of Grey's Anatomy's messages about the surgical field and female surgeons, and it discusses the potential learning outcomes and social effects.

Viewers of the series potentially cultivate a technologically optimistic image of surgery and, more precisely, the innovations of transplantation surgery. The representation of the competent and acknowledged Meredith Grey might eventuate more social trust in female surgeons, and Grey as a role model can 
encourage younger generations to apply for medical school. Grey's willingness to create a new surgical method to save the patient is heroic and empowering.

On the other hand, this representation of doctors might lead to high expectations for real doctors to provide groundbreaking treatments. A negative perception of doctors who use only proven methods might raise. Another potential harm is that the depiction of limitless possibilities in female surgical career and the absence of difficulties might have adverse effects as well. It is worth to consider Linsay M. Cramer's analysis on Grey's Anatomy that problematizes the lack of discourse about race in the series as the production depicts „a racially progressive, postracial, and color-blind society” (Cramer 2016, 474). As she writes, this obviates the presence of contemporary racism and its effects on individual and social levels. Representations like this „reverse the efforts of anti-racial movements and civil-right struggles and present this backward motion in a deceiving disguise of forward progress" $(2016,485)$. Thus, an overly optimistic representation of female surgical career might cover the existing struggles and the importance of those initiatives that aims to get equal opportunities for women in medicine.

The representation of the surgical procedures (just like the award winner abdominal wall transplant) and the setting of the series can enhance the cultivation effect. Creators of medical drama series aim to present hospitals, diseases, injuries, diagnostic and treatment procedures in a realistic manner and factual accuracy. Locational realism, including furniture and equipment, the medical language spoken by the characters, and the well-known visual symbols of doctors serve these aims. Perceived authenticity has a significant effect on the audience: because of the factual accuracy, the messages interpreted in and by this environment might be regarded as also accurate - this is how genre-specific cultivation comes into existence in this television genre. Furthermore, as Kato et al. (2017) clarify, emotional engagement with the fictitious content enhances the potential of entertainment-education. As the Introduction chapters show, the audience tends to learn from medical dramas, even though it is an entertaining genre that mixes facts with fiction. More emotional involvement leads to more attention to the content. The melodramatic storylines provide an opportunity to get emotionally involved with the depicted medical cases. Regarding the analyzed scene, the audience got an emotional background story: the patient spent a decade as a hostage in Iraq, where she took care of an orphaned boy, her brother, and groom work in the Grey-Sloan Memorial Hospital and they have a touching reunion. Grey tries to save the woman despite that she is having an affair with her groom, who thought that Hunt is dead.

Furthermore, the cultivation effect of Grey's Anatomy is reinforced or even enhanced by other television medical drama series that display competent female surgeons, such as The Good Doctor and The Residents. Furthermore, there are medical series that have skilled female doctor specialized in other fields of medicine - such as the heroic and challenging emergency medicine 
in which characters deal with life or death situations daily. Beyond medical series, it is also necessary to consider the effects of other genres of medically themed popular culture and media (for instance, medical reality shows) and other genres. Furthermore, the current period is a golden age of female protagonists in television - the different images of a competent female protagonist also reinforce the representation of Grey's Anatomy.

In summary, the analyzed series depicts a progressive, inclusive image of the surgical field that might be empowering for patients and new generations of doctors as well. However, the word that is represented by Grey's Anatomy is not a reality yet, because female surgeons face challenges today that should not be underestimated based on the optimistic but seemingly realistic - portrayal of the specialty. It is important to be conscious about the double effects of this representation of medical careers.

\section{References}

Adams, Annmarie. "Surgery and Architecture: Spaces for Operating." In The Palgrave Handbook of the History of Surgery, edited by Thomas Schlich, 261-81. London: Palgrave Macmillan, 2018.

Arawi, Thalia. "Using medical drama to teach biomedical ethics to medical students." Medical Teacher 32, no. 5, (2010): 205-210.

Bergen, van Leo. "Surgery and War: The Discussion About the Usefulness of War for Medical Progress.” In The Palgrave Handbook of the History of Surgery, edited by Thomas Schlich, 389-407. London: Palgrave Macmillan, 2018.

Bodoh-Creed, Jessica. "The ER Effect: How Medical Television Creates Knowledge for American Audiences”. In Teaching Medicine and Medical Ethics Using Popular Culture, edited by Evie Kendal and Basia Diug, 37-54. London: Palgrave Macmillan, 2017.

Brindley, P G and C Needham. "Positioning Prior to Endotracheal Intubation on a Television Medical Drama: Perhaps Life Mimics Art.” Resuscitation 80, no. 5, (2009): 604.

Brock, Claire. "Risk, Responsibility and Surgery in the 1890s and Early 1990s". Medical History 57, no. 3 (2013): 317-337.

Brock, Claire. "Women in Surgery: Patients and Practitioners." In The Palgrave Handbook of the History of Surgery, edited by Thomas Schlich, 133-52. London: Palgrave Macmillan, 2018. 
Brodie, Mollyann, Ursula Foehr, Vicky Rideout, Neal Baer, Carolyn Miller, Rebecca Flournoy and Drew Altman. "Communicating Health Information Through The Entertainment Media”. Health Affairs 20, no. 1, (2001): 192-199.

Brown, Michael. "Surgery and Emotion: The Era Before Anaesthesia. In The Palgrave Handbook of the History of Surgery, edited by Thomas Schlich, 327-48. London: Palgrave Macmillan, 2018.

Chory-Assad, Rebecca M., and Ron Tamborini. "Television Doctors. An Analysis of Physicians in Fictional and Non-Fictional Television Programs.” Journal of Broadcasting \& Electronic Media 45, no. 3. (2001): 499-521.

Chory-Assad, Rebecca M., and Ron Tamborini. “Television Exposure and the Public's Perception of Physicians.” Journal of Broadcasting \& Electronic Media 47, no. 2. (2003): 197-215.

Cooper, C P, D L Roter and A M Langlieb. "Using Entertainment Television to Build a Context for Prevention News Stories.” Preventive Medicine 31, no. 3, (2000): 225-31.

Cramer, Linsay M. "The Whitening of Grey's Anatomy.” Communication Studies 67, no. 4 (2016): 474-487.

Czarny, Matthew J., Ruth R. Faden, Marie T. Nolan, Edwin Bodensiek and Jeremy Sugarman. "Medical and Nursing Students' Television Viewing Habits: Potential Implications for Bioethics.” The American Journal of Bioethics 8, no. 12, (2008): 1-8.

Czarny, Matthew J., Ruth R. Faden and Jeremy Sugarman. "Bioethics and Professionalism in Popular Television Medical Dramas.” Journal of Medical Ethics 36, no. 4 (2010): 203-206.

Diem, Susan J., John D. Lantos, and James A. Tulsky. "Cardiopulmonary Resuscitation on Television - Miracles and Misinformation.” The New England Journal of Medicine 334, no. 24, (1996): 1578-1582.

Eisenman A., V Rusetski, Z. Zohar, D. Avital and J. Stolero. "Can popular TV medical dramas save real life?”. Medical Hypotheses 64, no. 4, (2005): 885.

Flicker, Eva. "Between brains and breasts - women scientists in fiction film: on the marginalization and sexualization of scientific competence.” Public Understanding of Science 12, (2003): 307-318.

Foss, Katherine A. "When We Make Mistakes, People Die: Construction of Responsibility for Medical Errors in Televised Medical Dramas, 1994-2007”. Communication Quarterly 59, no. 4, 484-506.

Frampton, Sally. "Opening the Abdomen: The Expansion of Surgery”. In The Palgrave Handbook of the History of Surgery, edited by Thomas Schlich, 175-94. London: Palgrave Macmillan, 2018.

Freytag, Jennifer and Srividya Ramasubramanian. "Are Television Deaths Good Deaths? A Narrative Analysis of Hospital Death and Dying in Popular Medical Dramas.” Health Communication 34, no. 7, (2019): 747-754.

Giele, Henk, Anil Vaidya, Srikanth Reddy, Giorgois Vrakas and Peter Friend. "Current state of abdominal wall transplantation”. Current Opinion on Organ Transplantation 21, no. 2, (2016): 159-164.

Gordon, PN, S Williamson, P G Lawler. "As seen on TV: observational study of cardiopulmonary resuscitation in British television medical dramas.” BMJ 317, (1998): 780-783.

Grabe, Maria Elizabeth and Dan G. Drew. "Crime Cultivation: Comparisons Across Media Genres and Channels.” Journal of Broadcasting \& Electronic Media 51, no. 1 (2007): 147-171. 
Harbaugh, Calista, Majed Afana, Stephanie Burdick, Joseph East, Sindhura Kodali, Jay Lee, Shaun Patel, Govind Rangrass, David Ranney, Vikram Sood, Raymond Lynch, Christopher J. Sonnenday, Michael J. Englesbe, Amit K. Mathur. "Portrayal of organ donation and transplantation on American prime-time television.” Clinical Transplantation 25, (2011): 375-380.

Harris, Dylan and Hannah Willoughby. "Resuscitation on television: Realistic or Ridiculous? A quantitative observational analysis of the portrayal of cardiopulmonary resuscitation in television medical drama.” Resuscitation 80, (2009): 1275-1279.

Haynes, Roslynn D. From Madman to Crime Fighter: The Scientist in Western Culture. Baltimore: Johns Hopkins University, 2017.

Hether, Heather J., Grace C. Huang, Vicki Beck, Sheila T. Murphy, and Thomas Valente. "Entertainment Education in a Media-Satured Environment. Examining the Impact of Single and Multiple Exposures to Breast Cancer Storylines on Two Popular Medical Dramas.” Journal of Health Communication. 13, no 8 (2008): 808-823.

Hinkelbein, Jochen, Oliver Spelten, Jörg Marks, Martin Hellmich, Bernd W Böttiger, Wolfgang A Wetsch. "An Assessment of Resuscitation Quality in the Television Drama Emergency Room: Guideline Non-Compliance and Low-Quality Cardiopulmonary Resuscitation Lead to a Favorable Outcome?”. Resuscitation 85, (2014): 1106-1110.

Hirt, Cassandra, Kerry Wong, Shannon Erichsen and Jonathan White. "Medical dramas on television: a brief guide for educators.” Medical teacher 35, no. 3, (2013): 237-242.

Hoffman, Beth L., Robert Hoffman, Charles B. Wessel, Ariel Shensa, Michelle S. Woods and Brian A. Primack. "Use of fictional medical television in health sciences education: a systematic review”. Advances in Health Science Education: Theory and Practice 23, no. 1, (2018): 201-208.

Houben, Carmen HM, Martijn A Spruit, Emiel FM Wouters and Daisy JA Janssen. „Am I Dying Doctor?”: How End-Of-Life Care is Portrayed in Television Medical Dramas”. Journal of Palliative Care \& Medicine 6, no. 1, (2016): http://doi.org/10.4172/2165-7386.1000247

Jain, Parul and Michael D. Slater. "Provider portrayals and patient-provider communication in drama and reality medical entertainment television shows.” Journal of health communication 18, no. 6, (2013): 703-722.

Jones, David S. "Surgery and Clinical Trials: The History and Controversies of Surgical Evidence. In The Palgrave Handbook of the History of Surgery, edited by Thomas Schlich, 479-501. London: Palgrave Macmillan, 2018.

Kato, Mio, Hirono Ishikawa,Tsuyoshi Okuhara,Masafumi Okada and Takahiro Kiuchi. "Mapping research on health topics presented in prime-time TV dramas in "developed" countries: A literature review.” Cogent Social Sciences, 3, (2017). https://doi.org/10.1080/233118 $\underline{86.2017 .1318477}$

Kendal, Evie and Basia Diug. "Introduction: The Use of Popular Culture in Medical and Health Education.” In Teaching Medicine and Medical Ethics Using Popular Culture, edited by Evie Kendal and Basia Diug, 1-16. London: Palgrave Macmillan, 2017.

Khalil, Georges E., and Lance S. Rintamaki. "A television entertainment-education drama to promote positive discussion about organ donation.” Health Education Research 29, no. 2. (2014): 284-296.

Kupi, Krisztina. “Ambivalens narratívák a transzplantáció tárgyalásában.” Médiakutató 12, no. 2, (2011): 83-94. 
Laudisio, Adriano. "Narration in TV Courtroom Dramas: Analysis of Narrative Forms and Their Popularizing Function.” ILCEA, 31, 2018, http://doi.org/10.4000/ilcea.4685

Lee, Tae Kyoung and Laramie D. Taylor. "The Motives for and Consequences of Viewing Television Medical Dramas.” Health Communication 29, (2014): 13-22.

Light, David et al. Total Abdominal Wall Transplantation: An Anatomical Study and Classification System, 2017.

McLemore, Elisabeth C., Sonia Ramamoorty, Carrie Y. Peterson, and Barbara L. Bass. "Women in Surgery: Bright, Sharp, Brave, and Temperate.” The Permanente Journal 16, no. 3 (2012): 54-59.

Mickel, Jason T. Shian-Li McGuire and Shelley Gross-Gray. "Grey’s Anatomy and Communication Accommodation: Exploring Aspects of Nonverbal Interactions Portrayed in Media.” Interpersona 7, no. 1, (2013): 138-149.

Morgan, Michael, and James Shanahan. "The State of Cultivation.” Journal of Broadcasting \& Electronic Media 54, no. 2 (2010): 337-355.

Murphy Sheila T., Heather J. Hether and Victoria Rideout (2008): How healthy is prime-time? An analysis of health content in popular prime time television programs. In Kaiser Family Foundation Report.

Nádasi, Eszter. "Changing the face of medicine, alternating the meaning of human: Medical innovations in Grey's Anatomy.” Critical Studies in Television: The International Journal of Television Studies. Vol. 11 (2). (2016): 230-243.

Nádasi, Eszter. “Orvos-beteg viszonyrendszerek az amerikai kórházsorozatokban.” Replika 105, (2017): 69-82.

Nayar A. et al. „A National Survey of Sexual Harassment Among Surgeons”. Academic Surgical Congress Abstract Archive. 2019.

Norredam, Marie and Dag Album. "Prestige and its significance for medical specialties and disease.” Scandinavian Journal of Public Health 35, no. 6 (2007): 655-661.

Obrecht, Sybille. "Transplantation Surgery: Organ Replacement Between Reductionism and Systematic Approaches”. In The Palgrave Handbook of the History of Surgery, edited by Thomas Schlich, 411-33. London: Palgrave Macmillan, 2018.

Pfau, M., L.J. Mullen, and K. Garrow. "The influence of television viewing on public perceptions of physicians.” Journal of Broadcasting \& Electronic Media 39, no. 4, (1995): 441-458.

Pokhrel, Lok. "How does Doctor-Patient Communication Differ Based on the Gender of Doctor and the Gender of Patient? An Analysis of Entertainment- Education Based Network Medical Drama Grey’s Anatomy”. Journalism \& Mass Communication Quarterly 5, no. 2, (2015): 7.

Pories, Susan E., Patricia L. Turner, Caprice C. Greenberg, Maya A. Babu and Sareh Parangi. "Leadership in American Surgery: Women Are Rising to the Top.” Annals of Surgery 269, no. 2, (2019): 199-205.

Portanova, Jaclyn, Krystle Irvine, Jae Yoon Yi, Susan Enguidanos. “It isn’t like this on TV: Revisiting CPR survival rates depicted on popular TV shows.” Resuscitation 96, (2015): 148-150.

Quick, Brian L. "The Effects of Viewing Grey's Anatomy on Perceptions of Doctors and Patient Satisfaction.” Journal of Broadcasting \& Electronic Media 53, no. 1, (2009): 38-55.

Quick, Brian L., Susan E. Morgan, Nicole R. LaVoie and Dave Bosch. “Grey’s Anatomy Viewing and Organ Donation Attitude Formation: Examining Mediators Bridging This Relationship Among African Americans, Caucasians, and Latinos”. Communication Research 41, (2014): 690-716. http://doi.org/10.1177/0093650213475476 
Quigley, Meghan A., Derek R Fletcher, Wensheng Zhang, Vu T Nguyen. "Development of a Reliable Model of Total Abdominal Wall Transplantation.” Plastic and Reconstructive Surgery 132, no. 4, (2013): 988-994.

Rideout, Victoria (2008): Television as a health educator: a case study of Grey's Anatomy. In: Kaiser Family Foundation Report.

Schlicht, Thomas. "Surgery, Science and Modernity: Operating Rooms and Laboratories as Space of Control.” History of Science 45, (2007): 231-256.

Snow, Stephanie J. "Surgery and Anaesthesia: Revolution in Practice.” In The Palgrave Handbook of the History of Surgery, edited by Thomas Schlich, 195-214. London: Palgrave Macmillan, 2018.

Spike, Jeffrey. "Television Viewing and Ethical Reasoning: Why Watching Scrubs Does a Better Job Than Most Bioethics Classes.” The American Journal of Bioethics 8, no. 12, (2008): 11-13.

Turow, Joseph. Playing Doctor: Television, Storytelling, and Medical Power. Ann Arbor: The University of Michigan Press, 2010.

Valente, Thomas W., Sheila Murphy, Grace Huang, Jodi Gusek, Jennie Greene, Vicki Beck. "Evaluating a Minor Storyline on ER About Teen Obesity, Hypertension, and 5 A Day". Journal of Health Communication 12, no. 6, (2007): 551-66.

Van den Bulck, Jan J.M. "The impact of television fiction on public expectations of survival following inhospital cardiopulmonary resuscitation by medical professionals.” European Journal of Emergency Medicine 9, no. 4, (2002): 325-9.

Weaver, Roslyn és Ian Wilson. "Australian medical students' perceptions of professionalism and ethics in medical television programs.” BMC Medical Education 11, no. 1, (2011). https://doi.org/10.1186/1472-6920-11-50

Weaver, Roslyn, Ian Wilson, and Vicki Langendyk: "Medical professionalism on television: Student perceptions and pedagogical implications.” Health 18, no. 6, (2014): 597-612.

White, Gladys B. "Capturing the ethics education value of television medical dramas." The American Journal of Bioethics 8, no. 12, (2008): 13-14.

Wicclair, Mark R. "The Pedagogical Value of House, MD—Can a Fictional Unethical Physician Be Used to Teach Ethics?”. The American Journal of Bioethics 8, no. 12, (2008): 16-17.

Wirtzfeld, Debrah A. "The history of women in surgery.” Canadian Journal of Surgery 52, no.4 (2009): 317-320.

Yue-Yung, Hu, Ryan J. Ellis, D. Brock Hewitt, Anthony D. Yang, Elaine Ooi Cheung, Judith T. Moskowitz, John R. Potts, Jo Buyske, David B. Hoyt, Thomas J. Nasca and Karl Y. Bilimoria. "Discrimination, Abuse, Harassment, and Burnout in Surgical Residency Training." The New England Journal of Medicine 381, (2019): 1741-1752. 